\author{
Available online at https://www.rjtl.org \\ Volume: 1, Issue: 3, 59-63, 2020 \\ ISSN: $2708-3632$ \\ DOI: https://doi.org/10.46590/rjtl.2020.010301
}

\title{
Apparel Industry - The New Normal.
}

\author{
J.M. Subashini ${ }^{1}$, S. Kanchana Devi ${ }^{1}$, Dr. S. Kavitha ${ }^{2}$ \\ ${ }^{1} \mathrm{M}$. Tech Scholar, ${ }^{2}$ Assistant Professor, \\ Department of Fashion Technology, Kumaraguru College of Technology, Coimbatore.
}

\section{Paper History}

Received : September 2020

Accepted : October 2020

Published : November 2020

Corresponding Author

J.M. Subashini

subashini.19mat@kct.ac.in

\begin{abstract}
In the post-COVID-19 pandemic wearing the mask and maintaining social distancing becomes the new normal where people have to strictly follow to keep themselves safe. In such situations, the apparel industry has to come up with new business imperatives to catch up with their business back to normal. The world has to face new strategies and new adaptation to overcome the pandemic time and move back to a new normal. The apparel sectors, brand, retail, the manufacture has faced many challenges and thus in this paper, the challenges of textile and apparel sectors and new norms and strategies followed by apparel brand, in retail sectors, buying and in supply chain management has been discussed and it is found that digitalization has become new normal in all of these sectors.
\end{abstract}

Keywords: Apparel manufacturing, brand, retail, digital network, virtual trade, supply chain

Citation: J.M. Subashini, S. Kanchana Devi, Dr. S. Kavitha, Apparel Industry - The New Normal. Research Journal of Textile and Leather, 1(3), 59-63, 2020.

\section{INTRODUCTION}

The never imagined pandemic which occurs due to Covid-19 has drastically changed the life of every industrial sector which includes manufacturers, buyers, and retailers. The global economy has also weakened so that people have to come over with the new normal to overcome the crisis. Because of the apparel industry, they face many challenges in inventory, supply chain, delivering and keeping their facility in a safe environment. Though apparel is considered as nonessential goods they face many significant challenges and drop in sales and it is more important to adopt new ways and strategies to reach and engage the customer to shop more products to balance their economy. Meanwhile, the apparel sectors are started making PPE and masks which is considered as most essential in preventing people's life. This is suitable for large-scale manufactures, where they can shift over to the production of PPE with suitable machinery. But in the case of small-scale sectors, they could not change over without proper machinery and cost for manufacturing also, other than a few apparel manufacturing industry it is not possible to shift over to PPE manufacturing economically. For the upcoming fiscal year, the apparel sectors are at high-risk factors for managing their global economy, and also their manufacturing of goods will be initially low which could be then gradually increased in the latter half. Thus the apparel sectors have to adopt a new normal ie., new strategies, and new behaviours to integrate into the manufacturing process, inventory, retailing, brands, supply chain, and customer behaviour.

\section{POST COVID-19 BUSINESS IMPERATIVES}

\subsection{Textile and Apparel Manufacturing}

In textile sectors, the scope for import substitution exists in technical textiles as the Indian textile industry depends mainly on cotton whereas, most of the synthetic raw materials like PSF, PTA, PFY, acrylic fibers, etc. are imported. Though COVID-19 creates many changes in the textile sectors, it creates opportunities for the stakeholders to invest and create a new market for technical textiles [1].

For small scale garment manufacturing sectors there would be cascading effects on the suppliers of this industry, but once after the industry recovers, there would be an ample opportunity for enhancing the export market shares [1].

\subsection{Impact in Apparel brand}

Due to the effect of COVID-19 in India, the apparel shares have been lost up to 50-60\% in the first quarter of FY21. This is because store closures have led to huge inventory pile-up, also spring-summer collection is still to be spread out over a longer period and the 
production of the autumn-winter collection has not yet to be started. Depending upon all these factors, many brands started following some new strategies [2].

Table 1. Challenges and Opportunities for Indian Textile Sector

\begin{tabular}{ll}
\hline Changes brought by Post & $\begin{array}{l}\text { Opportunities } \\
\text { created for } \\
\text { Stakeholders }\end{array}$ \\
\hline
\end{tabular}

Unstable and Uncertain
Economy (opens the door
for the new ecosystem)
More respect for protocols
(effectively increasing
usage of protective gears
etc)

Increased fear of safety

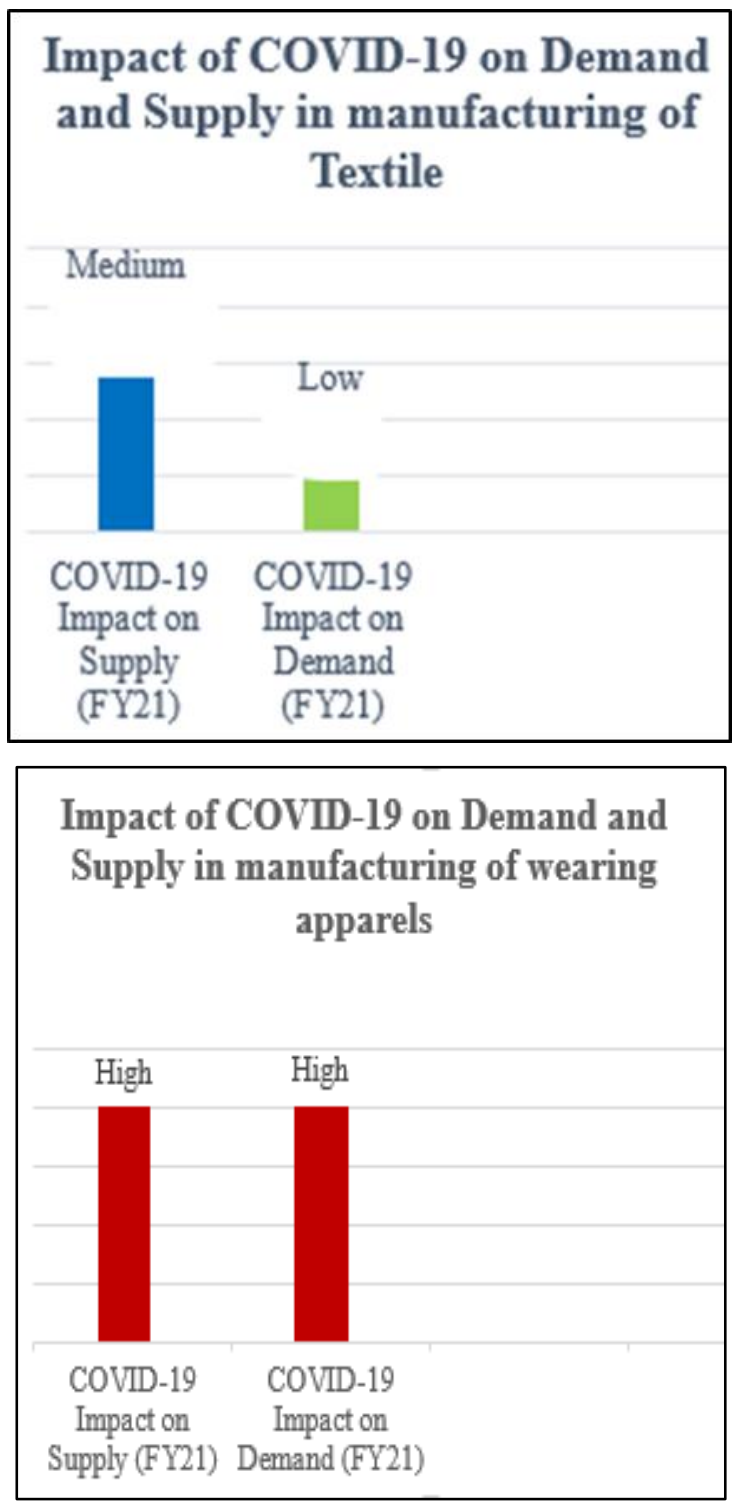

Figure 1. Impact on Demand and Supply in India
Many apparel companies are taking to mitigate losses due to renegotiating rents, maintenance of stores, and utilizing the leftover inventory. To overcome these losses, the apparel company like Raymond effectively manages the liquidity with an increased focus on payment the realization of the market. Also, the company is working on measures for cost rationalization by cutting down all non-critical expenses and market spending. To increase product sales, Raymond launched its online tailoring initiative; the company is planning to scale this up [3].

Lifestyle is also planning to go Omni-channel to offer choice and comfort to the customer for a seamless shopping across the digital platform. The company also mentioned that they have been equipped themselves to handle a higher volume of deliveries for their ecommerce vertical and they made adequate arrangements to balance the product demand. In physical stores, they provide a sanitizer station and floor marker for maintaining social distancing between the customers. Lifestyle has taken adequate precautions to reduce direct contact with the customer by making contactless payment and discounting services like make-over and testers [3].

The international brand Nike drove a strong digital marketing campaign as a response to the negative demand blow to its store and also to engage their customer across the globe during the lockdown, so that their digital commerce remains open and also in growth mode, get supported by their employers and their distribution centres [4]. Though the brands are marketing their business in digital platforms, they face many challenges in handling the physical store as safety is highly prioritized by the customer. The critical point where people highly think about is the usage of the trail room. Some fashion brand like Jockey has said no trail or exchange. The brands like Levis, Soch, and Max have a blanket trail-room policy. After each time the trail room has been cleaned and the cloths are been ironed to prevent the virus from spreading. Only up to a maximum of 3 items are been allowed to the customer to make the trails.

\subsection{Retailing-New Norms with Integrated Environment}

In the case of retailing, retailers must think of the immediate changes to be made to survive in the market which is to be instigated now after the lockdown and later which will be the new normal. The main focus of the retailers will be how they can efficiently provide the customer what their needs are. The supply chain, inventory, and the delivery system are made to reconsider new ways in retail management with high safe ends [5]. 


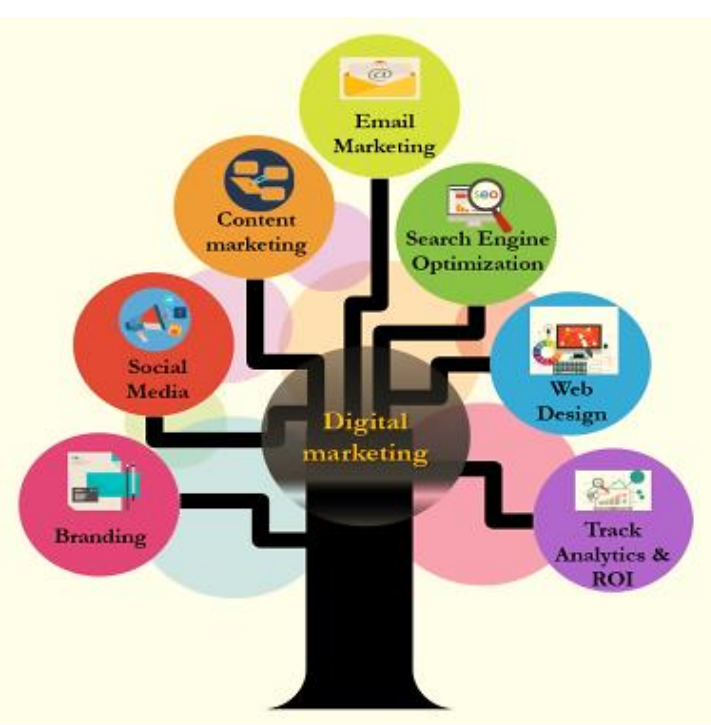

Figure 2. Digital Marketing Network

In apparel manufacturing, the retailers are the main sectors to deliver the final product to the customer. Due to the COVID-19 pandemic, the product stock retains unsold which causes a delay for next season manufacturing of apparel goods. To overcome these issues retailers are moving into an integrated environment where they sell products online, which paws the way for visualization of the product by the customer, easy payment ways, easy return in the cause of defects, and high privacy security for fraud exposures [6,7]. Also, many retailers and brands are interconnected in the same online platform to enhance easy buying to the customer. To prevent the website traffic proper SEO is maintained to increase the visibility of the website or a web page to the user. Digital marketing allows us to connect with more customer and in post-pandemic digital marketing opens many opportunities for the retailers to enhance and make their business wider and a successful one [8]. The digital marking platform provides an integrated environment to engage the customer via social media networks, emails, ads, etc. (fig.2) with many offers and discounts. For apparel retail stores, the prevention guidelines have been given by the Retail Association of India (RAI) for customer journey at the store that how they should act at each stage from the store entrance, baggage counter, trail room, customer sales desk, billing \& payment and exit way [9]. Some of the new ways and ideas for developing an essential retail business are listed in fig 3. These new ways can provide an add-on to them to make a good retail job in favour of the customers.

\section{VISUALIZATION IN BUYING - NEW GENERATION TRADE FAIR}

The technology with virtual reality and AI helps to promote the virtual platform which aims to combat the lack of sales because physical fair worldwide has been cancelled due to the outbreak of COVID19. The Virtual trade Expo started by Fiber2fashion in the name of F2F Sourcing Show 2020 - The Virtual Trade fair. This brings the leading manufacturer and importers of apparel and textile sectors under one roof of a virtual platform where they could find separate halls for Apparel, Yarn, Fabric, and Textile machinery like a physical exhibition. In each hall separate booths with an interactive setup of all important features like product showcase, profile, business card, exchange, live chat, video conferencing, and many more[16]. IHGF (Indian handicraft and gift fair) 2020 - a virtual textile fair for home textile, fashion \& lifestyle, accessories, and others organized by Export Promotion Council of Handicraft. This expo aims to connect with over 1500 suppliers in a real-time event worldwide. V Tex Show - Virtual Textile Exhibition organized by The Textile Excellence is trying to re-energizing the business in a new real way into the world of virtualization.

\section{NEW ADAPTATION IN SUPPLY CHAIN}

As clothing outlets have been shut by lockdown, many brands and retailers have cancelled their orders or postpone production orders which heavily affects many manufacturing sectors which also leads to many unemployment and pay cut off to the workers[10]. There has been a significant reduction in orders and cash flow across the industries which cause a deep hit across the industries which made the supply chain into a high-risk factor. To reduce the risk factors caused by the pandemic, it is suggested that the global sourcing can be balanced by near-shore and local sourcing. The adoption of multiple sourcing can be enhanced with the greater support and utilization of information technology that can direct, monitor, track, and respond immediately over the orders [12]. The digital supply chain network is designed to anticipate disruption and configure itself to mitigate their respective impacts. The digital supply chain module will be a new business strategy to formulate an integrated environment with perspective to risk management. The resilient supply chain can be followed to reduce the risk and help us to quickly recover from the unanticipated supply chain disruptions that occur [13].

To overcome the pandemic and balance the crisis occurs in the field of the supply chain it is more important to promote the supply chain management not just on cost but also on resilience and to improve decision-making models. The decision models for supply chain design should be made by avoiding overfocusing on cost and mainly consider the value of flexibility which enriches multiple sourcing and short response time. The process of adapting the visible supply chain model by the companies will be useful in 


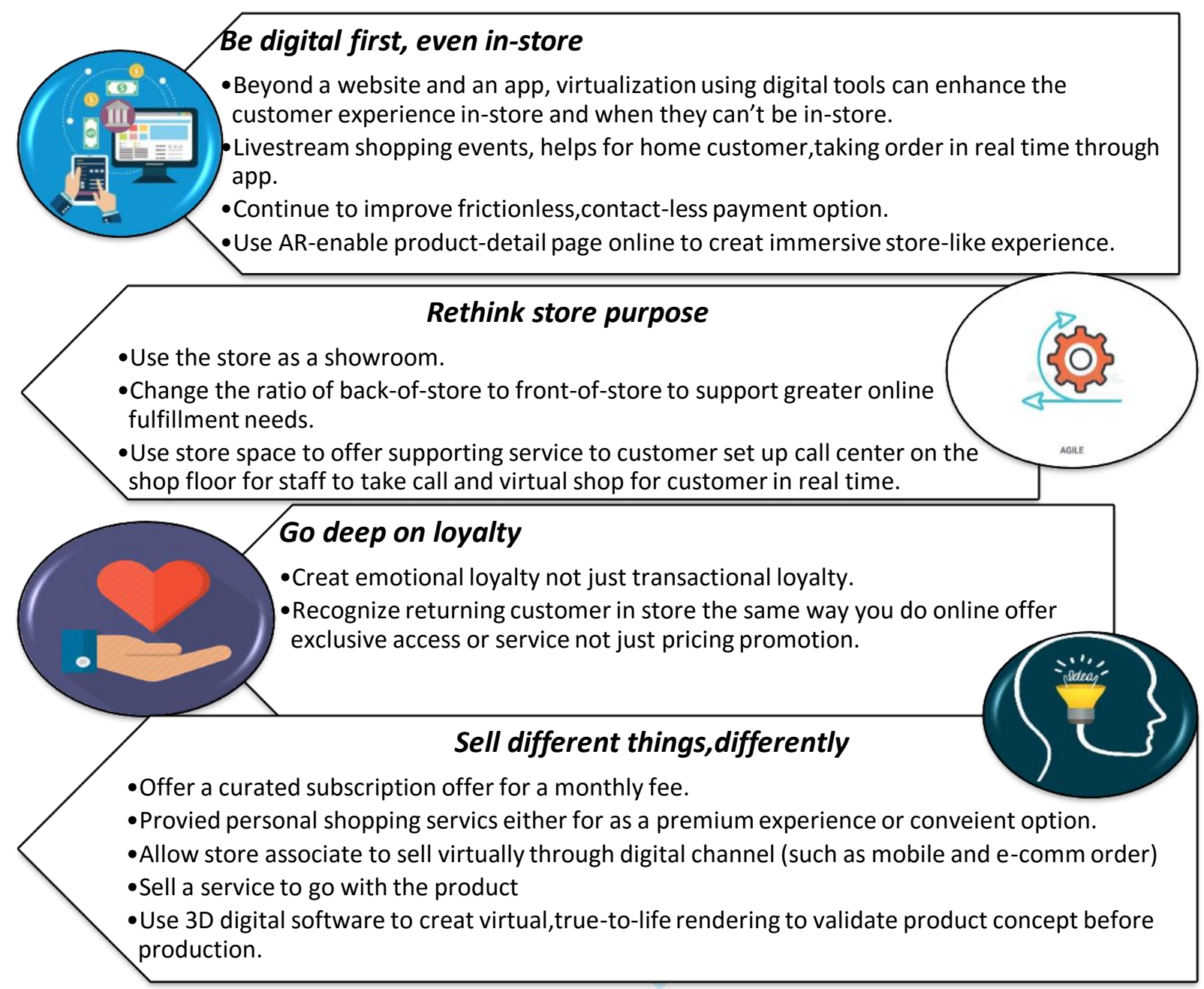

Figure 3. New ideas and suggestions for essential retail business in Post Covid-19

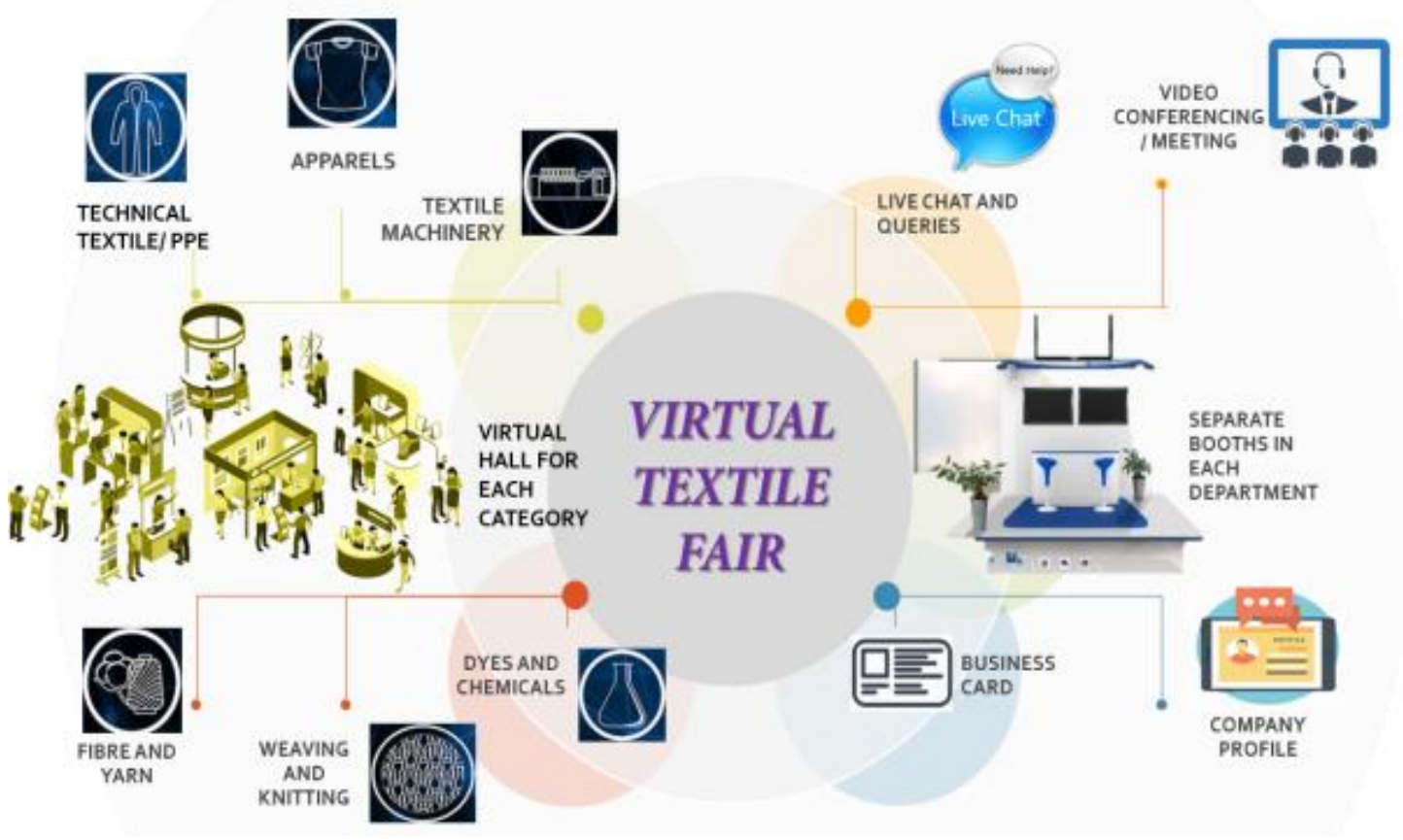

Figure 3. New Generation Virtual fair 
Understanding the new strategies of the supply chain ecosystem where the agility, resilience, and survivability is being followed [15]. Also while talking about the time horizons in the supply chain, the decision-makers say that reshoring will be a way to cope up with the current condition, where the supply chain may either face a transitory condition before coming to normal or adapt to new normality [14].

\section{CONCLUSION}

The new imperatives in the apparel business brand, retail business, and supply chain have been discussed in this paper. Also, the impact of COVID-19 on the textile and apparel sectors has been seen. In the postpandemic, the world has to come over with new plans and ideas using future technology in the apparel business which creates a safer side to face and overcome such a pandemic situation. Also, the postCOVID-19 business imperatives have made the customers move into a digital platform and safe shopping of apparel products. The supply chain also moves to a digital network where business communication can be made effectively where the company can be in a safe environment.

\section{REFERENCES}

[1] https://dst.gov.in/sites/default/files/Focused\% 20Interventions $\% 20$ for $\% 20 \% \mathrm{E} 2 \% 80 \% 98 \mathrm{Mak}$ e\%20in\%20India\%E2\%80\%99\%20Post\%20C OVID\%2019\%20-\%20TIFAC.pdf.

[2] www. business today.in > story Coronavirus in India: Apparel brands stare at 50-60\% loss in first.

[3] https://www.thehindubusinessline.com/econo my/fashion-industry-draws-action-plan-forpost-covid-19-situation/article31555037.ece.

[4] Li, Kai, et al. "The role of corporate culture in bad times: Evidence from the COVID-19 pandemic."

Available at SSRN 3632395 (2020).

[5] Roggeveen, Anne L., and Raj Sethuraman. "How the COVID Pandemic May Change the World of Retailing." Journal of Retailing (2020).

[6] Sun Jiong, Zhang Xing, Zhu Qingyuan. Counterfeiters in Online Marketplaces: Stealing Your Sales or Sharing Your Costs. Journal of Retailing. 2020;96(June (2)):189202.

[7] Brough, Aaron R., and Kelly D. Martin. "Consumer Privacy During (and After) the COVID-19 Pandemic." Journal of Public Policy \& Marketing (2020)
[8] Azevedo, Antonio, and Minoo Farhangmehr. "Clothing branding strategies: Influence of brand personality on advertising response." Journal of Textile and Apparel, Technology and Management 4.3 (2005): 1-13.

[9] https://rai.net.in/images/Apparel\%20RetailGuidelines.pdf

[10] McMaster, May, et al. "Risk Management: Rethinking Fashion Supply Chain Management for Multinational Corporations in Light of the COVID-19 Outbreak." Journal of Risk and Financial Management 13.8 (2020): 173.

[11] Sneader, Kevin, and Bob Sternfels. "From surviving to thriving: Reimagining the postCOVID-19 return." New York: McKinsey \& Company (2020).

[12] Remko, v.H. (2020), "Research opportunities for a more resilient post-COVID-19 supply chain - closing the gap between research findings and industry practice", International Journal of Operations \& Production Management, Vol. 40 No. 4, pp. 341-355.

[13] www2.deloitte.com > finance PDF COVID-19 - Managing supply chain risk and disruption Deloitte

[14] Barbieri, Paolo, et al. "What can we learn about reshoring after Covid-19?." Operations Management Research (2020): 1-6

[15] Ivanov, Dmitry. "Viable supply chain model: integrating agility, resilience and sustainability perspectives-lessons from and thinking beyond the COVID-19 pandemic." Annals of Operations Research (2020)

[16] https://www.fiber2fashion.com/news/textilenews/fiber2fashion-s-virtual-trade-expo-goeslive-269250-newsdetails.htm

[17] Subashini, J. M. "Pandemic Protective Wear for Healthcare Personnel." 